\title{
Dessorção de fósforo avaliada por extrações sucessivas em amostras de solo provenientes dos sistemas plantio direto e convencional ${ }^{1}$
}

\author{
Phosphorus dessorption evaluated by successive extractions of soils samples \\ under no tillage and conventional tillage systems
}

\section{Danilo dos Santos Rheinheimer ${ }^{2}$ Ibanor Anghinoni $^{3} \quad$ Elaine Conte $^{4}$ João Kaminski ${ }^{5}$ Luciano Colpo Gatiboni ${ }^{6}$}

RESUMO

O fósforo é retido à fase sólida do solo com diversas energias de ligação, dependentes das características e quantidade dos colóides do solo. A adoção do sistema plantio direto (SPD) pode promover o acúmulo de fósforo em formas diferentes daquelas observadas no sistema de cultivo convencional (SCC) e, assim, modificar as características de dessorção do fósforo do solo. O objetivo deste trabalho foi avaliar a capacidade de dessorção de fósforo em solos submetidos a sistemas de cultivo. Três solos com teores variáveis de argila (Latossolo Vermelho Distroférrico $680 \mathrm{~g} \mathrm{~kg}^{-1}$ de argila, Latossolo Vermelho Distrófico - $530 \mathrm{~g}$ $\mathrm{kg}^{-1}$ de argila e Argissolo Vermelho Distrófico - $220 \mathrm{~g} \mathrm{~kg}^{-1}$ de argila) cultivados sob SPD e SCC foram submetidos a extrações sucessivas com resina trocadora de anions (RTA) e ajustadas equações de cinética de primeira ordem para estimar a capacidade de dessorção máxima do solo. A dessorção da primeira extração e dessorção máxima de fósforo foram maiores na camada superficial do solo sob $S P D$, comparativamente ao SCC. Uma única extração com RTA representou, em média, 38, 46 e 49\% do fósforo dessorvível para o solo muito argiloso, argiloso e arenoso, respectivamente, enquanto a estimativa pelo extrator Mehlich 1 representou, para os mesmos solos, 32, 46 e 89\% da dessorção máxima de fósforo.

Palavras-chave: fósforo, extratores químicos, sistema plantio direto, labilidade.

\begin{abstract}
The phosphorus is retained in the soil solid phase with several degrees of energy, which depends on the characteristics and amount of the soil colloids. The no tillage system (NT) may promote phosphorus accumulation in different forms from those observed in the conventional tillage (CT) and thus, may modify the dessorption capacity of the soil. The objective of this work was to estimate the phosphorus dessorption capacity of different soils submitted to NT and CT. Samples from three soils with variable clay contents (Rhodic Hapludox - $680 \mathrm{~g} \mathrm{~kg}^{-1}$ clay, Rhodic Hapludox - $530 \mathrm{~g} \mathrm{~kg}^{-1}$ clay and Rhodic Paleudult - $220 \mathrm{~g} \mathrm{~kg}^{-1}$ clay) cultivated under NT and CT were submitted to successive extractions with anion exchange resin ( $A E R$ ) and adjusted first order kinetics equations to estimate the maximum phosphorus dessorption of the soil. The dessorption by the first extraction and maximum dessorption were higher in the superficial layer of the soil under NT, comparatively to CT. Only one extraction with AER represented, on average, 38, 46 and $49 \%$ of the maximum dessorption on soils with high, medium and low clay content, respectively, while that estimated by Mehlich 1 extractor represented, for the same soils, 32,46 and $89 \%$ of the maximum dessorption.
\end{abstract}

Key words: soil phosphorus, soil extractants, no-tillage system, lability

${ }^{1}$ Parte da tese de doutorado do primeiro autor. Financiado pela FAPERGS.

${ }^{2}$ Engenheiro Agrônomo, Doutor em Ciência do Solo, Professor Adjunto, Departamento de Solos, Universidade Federal de Santa Maria (UFSM), Campus Universitário, 97105-900, Santa Maria, RS. Bolsista do CNPq. Email:danilo@ccr.ufsm.br Autor para correspondência. ${ }^{3}$ Engenheiro Agrônomo, Doutor em Ciência do Solo, Professor Adjunto, Departamento de Solos,UFRGS. Bolsista do CNPq.

${ }^{4}$ Engenheiro Agrônomo, Mestre em Agronomia.

${ }^{5}$ Engenheiro Agrônomo, Doutor em Ciência do Solo, Professor colaborador, Departamento de Solos, UFSM e Professor da UNIFRA. Bolsista do CNPq.

${ }^{6}$ Engenheiro Agrônomo, Mestre em Agronomia, Doutorando no Programa de Pós-graduação da UFSM 


\section{INTRODUÇÃO}

O fosfato é adsorvido especificamente aos grupos funcionais monocoordenados aos óxidos, arestas das argilas e aluminossilicatos amorfos, os quais são de fácil protonação, promovendo as reações de troca de ligantes. A adsorção de fósforo ocorre em três estádios temporais. No estádio I, predomina a neutralização das cargas positivas, que são saturadas quando todos os grupos $\mathrm{R}-\mathrm{OH}_{2}{ }^{+}$forem compartilhados pelos íons fosfatos; no estádio II, ocorrem as trocas de ligantes e, no estádio III, interações de caráter físico entre o fosfato e a superfície dos colóides inorgânicos (PARFITT et al., 1975; RYDEN et al., 1977; PARFITT, 1989). Portanto, a reversibilidade destas reações, denominada dessorção, é dependente da proporção de ocupação dos sítios de adsorção, ou de outros fatores que alteram a magnitude da energia de ligação deste elemento com os colóides do solo. Deste modo, a capacidade de extração dos métodos de avaliação da disponibilidade está vinculada a essa energia de adsorção.

Por isso, a utilização de uma única extração pode não ser suficiente para estimar o fósforo potencialmente disponível às plantas (CAMPELLO et al., 1994; GATIBONI et al., 2002), pois esse nutriente é acumulado em diversas formas no solo (TIESSEN et al., 1992; BECK \& SANCHEZ, 1994; DAROUB et al., 2000), cujas cinéticas de dessorção são dependentes de sua interação com os colóides (HEDLEY et al., 1982; BECK \& SANCHEZ, 1994; GUO \& YOST, 1998; GUO et al., 2000). Devido à subestimação do fator quantidade pelos métodos de rotina, alguns autores recomendam o uso de extratores com maior poder de extração, como o NaOH 0,1 mol ${ }^{-1}$ (BALL-COELHO et al., 1993; BECK \& SANCHES, 1994; GUO \& YOST, 1998; RHEINHEIMER et al., 2000).

As características de dessorção de fósforo do solo podem ser estimadas mediante extrações sucessivas com resina trocadora de ânions (HAGGAR et al, 1991; CAMPELLO et al., 1994; McKEAN \& WARREN, 1996), pois esse é um procedimento não destrutivo (GATIBONI et al., 2002). Desta maneira, McKEAN \& WARREN (1996) verificaram que, para um grupo de solos altamente intemperizados, foram necessárias quatro extrações sucessivas para que a liberação de fósforo cessasse em solo sem adição de fertilizantes e de oito para recuperar o fósforo recentemente adicionado ao solo. Através dos valores de dessorção máxima, esses autores conseguiram separar tratamentos que apresentavam valores semelhantes de fósforo disponível. No entanto, embora o valor da dessorção máxima tenha sido muitas vezes superior ao fósforo disponível, foi menor do que a quantidade adicionada. A defasagem entre o adicionado e o total dessorvido, fenômeno denominado histerese, deve-se às transformações que ocorrem após a adsorção do fosfato, que aumentam a afinidade deste com a superfície dos colóides (BARROW, 1983).

No sistema plantio direto (SPD), o volume de solo fertilizado é pequeno, pois há o revolvimento apenas no sulco de semeadura, sendo facilmente saturados os sítios de adsorção da camada superficial (RHEINHEIMER \& ANGHINONI, 2001). Adicionalmente, é de se esperar que a capacidade de adsorção do solo seja diminuída à medida que o sistema se consolide, pois as perdas de fósforo neste sistema são pequenas, há freqüentes adições de fertilizantes e ocorre a ciclagem de fósforo das camadas mais profundas para a camada superficial. Também, por causa de maiores teores de ânions orgânicos, que podem competir química e fisicamente com o fosfato pelos sítios de adsorção, as reações de sorção são amenizadas (SIBRANDA \& YOUNG, 1986; HUE, 1991).

OLOYA \& LOGAN (1980) demonstraram, através da extração seqüencial, que na camada superficial do SPD há maior contribuição no fósforo dessorvido por unidade de fósforo disponível, quando comparado ao sistema de cultivo convencional (SCC), indicando que esse nutriente permanece mais lábil no SPD. GUERTAL et al. (1991) mostraram que em solos cultivados por longo período sob SPD, a quantidade de fósforo dessorvido pela extração seqüencial com resina foi mais rápida e em maior quantidade na camada $0-2 \mathrm{~cm}$, em relação às camadas de 2-6 e 6-8cm. Após a dessorção, a capacidade de adsorção de fósforo foi maior para todas as profundidades, mas especialmente para a camada superficial. A maior dessorção se deve então às adições superficiais de fertilizantes e não ao revolvimento do solo, o que satura os sítios na camada superficial do solo e, adicionalmente, a maior quantidade de matéria orgânica nessa camada. Assim, espera-se que no solo conduzido sob SPD, o fósforo acumulado permaneça em formas mais disponíveis (CONTE, 2001), apresentando maior desortividade em relação ao solo sob SCC.

Este trabalho teve por objetivo determinar o potencial de dessorção do fósforo de solos com diferentes teores de argila, conduzidos sob sistema de cultivo convencional e plantio direto.

\section{MATERIAL E MÉTODOS}

As amostras de solo utilizadas neste trabalho foram coletadas em 1997 em experimentos 
de longa duração, instalados sobre três tipos de solos, que objetivavam o estudo dos efeitos de métodos de preparo do solo na recuperação da qualidade do solo.

O primeiro experimento foi instalado em 1979, num Latossolo Vermelho Distroférrico típico muito argiloso, substrato basalto (LVdf - Rhodic Hapludox - EMBRAPA, 1999) no Centro de Atividades Agrícolas e Florestais da Cooperativa Tritícola de Santo Ângelo - RS. A área tinha sido anteriormente cultivada por 15 anos em cultivo convencional e apresentava avançado estado de degradação física. Na implantação do experimento, em 1985 e, posteriormente, em 1992, aplicou-se calcário para elevar o $\mathrm{pH}$ em água até 6,0 (método SMP). A adubação usada a partir da instalação do experimento seguiu a recomendação técnica específica de cada cultura, sendo aplicados, em cada cultivo comercial, $22 \mathrm{~kg}$ ha $^{-1}$ de $\mathrm{P}_{2} \mathrm{O}_{5}$. As amostras de solo foram coletadas nas parcelas do SPD e nas do SCC, na sucessão de culturas trigo (Triticum aestivum L.) / soja (Glycine max (L.) Merrill). As amostras de solo foram coletadas nas parcelas que nunca receberam adubação nitrogenada, na expectativa de que maior quantidade de fósforo se acumularia no solo, uma vez que a exportação pelas colheitas era menor.

O segundo experimento foi instalado, em 1983, num Latossolo Vermelho Distrófico típico argiloso, substrato basalto (LVd - Rhodic Hapludox - EMBRAPA, 1999) no Centro Nacional de Pesquisa do Trigo EMBRAPA, em Passo Fundo - RS. As amostras foram coletadas nos tratamentos SPD e SCC, nos blocos cultivados com soja em uma seqüência de culturas alternadas no tempo, envolvendo ervilhaca (Vicia sativa L.), milho (Zea mays L.), sorgo (Sorghun bicolor L.), aveia preta (Avena strigosa Screb), soja e cevada (Hordeum vulgare L.). Foi aplicado calcário na implantação do experimento e reaplicado em 1989, com incorporação ao solo, na dose recomendada para elevar o pH até 6,0 e a adubação usada seguiu as recomendações técnicas, sendo aplicados $17,5 \mathrm{~kg} \mathrm{ha}^{-1}$ ano $^{-1} \mathrm{de}_{2} \mathrm{O}_{5}$

$\mathrm{O}$ terceiro experimento foi instalado, em 1985, num Argissolo Vermelho Distrófico típico textura franco argilo-arenosa (PVd - Rhodic Paleudult EMBRAPA, 1999) em Eldorado do Sul - RS, pelo Departamento de Solos da Universidade Federal do Rio Grande do Sul. Na implantação do experimento, a adubação foi incorporada ao solo e as demais aplicações foram feitas na superfície, sendo aplicados, em média, $20 \mathrm{~kg} \mathrm{ha}^{-1}$ ano $^{-1}$ de $\mathrm{P}_{2} \mathrm{O}_{5}$. O solo foi amostrado nos tratamentos SPD e SCC na sucessão de culturas aveia+ervilhaca/milho+caupi (Vigna unguiculata subs unguiculata (L.) Walp).
Em maio de 1997, logo após o preparo do solo, coletaram-se amostras de solo nos três experimentos, em duas repetições de cada tratamento, nas profundidades de 0-2,5, 2,5-7,5 e 7,5-17,5cm. Cada amostra foi composta pela homogeneização de duas subamostras oriundas de trincheiras de $50 \times 10 \times 17,5 \mathrm{~cm}$, coletadas perpendicularmente às linhas de semeadura. O solo foi seco ao ar e peneirado em malha de $1 \mathrm{~mm}$. O resultado da caracterização química, mineralógica e granulométrica dos solos está apresentado na tabela 1 .

Foram determinados os teores de fósforo disponível pelo extrator Mehlich 1 (TEDESCO et al., 1995); a capacidade de dessorção de fósforo do solo foi obtida por extrações sucessivas com RTA. Este procedimento consistiu em acondicionar $0,5 \mathrm{~g}$ de solo seco ao ar $(<1,0 \mathrm{~mm})$ em tubo de centrífuga com tampa rosca, no qual se adicionaram $30 \mathrm{ml}$ de água destilada e uma lâmina de 7,5 $\mathrm{cm}^{2}$ de RTA (AR 103 QDP 434 Ionics Inc.) saturada com $\mathrm{NaHCO}_{3} 0,5 \mathrm{~mol} \mathrm{l}^{-1}$. As amostras foram agitadas por 16 horas em agitador tipo "end-over-end" (30rpm) a $25^{\circ} \mathrm{C}$. Após, as membranas de resina foram eluídas em $50 \mathrm{~mL}$ de $\mathrm{HCl} 0,5 \mathrm{~mol} \mathrm{l}^{-1} \mathrm{e} o$ teor de fósforo no extrato foi determinado de acordo com MURPHY \& RILEY (1962). Repetiu-se a extração com RTA sucessivamente até que o teor de fósforo extraído tornou-se constante e próximo a zero. Entre uma extração e outra, o solo permaneceu em repouso e saturado com água por sete dias.

Ajustou-se a equação de cinética de primeira ordem, $P_{\text {dessorvido }}=b-(b-a)^{\text {-kt }}$ proposta por McKEAN \& WARREN (1996), na qual $b$ é o fósforo potencialmente dessorvível ou dessorção máxima, $a$ é a quantidade de fósforo dessorvido na primeira extração, $k$ é a taxa de dessorção constante e $t$ é o tempo. Os efeitos dos preparos do solo e das profundidades de amostragens nos parâmetros $a, b$ e $k$ foram avaliados através de teste de comparação de médias Tukey $(\mathrm{p}<0,05)$.

Tabela 1 - Características químicas, mineralógicas e granulométricas dos solos estudados.

\begin{tabular}{lccc}
\hline Característica & LVdf & LVd & PVd \\
\hline Argila $\left(\mathrm{g} \mathrm{kg}^{-1}\right)$ & 680 & 530 & 220 \\
$\mathrm{Fe}_{\mathrm{d}}\left(\mathrm{g} \mathrm{kg}^{-1}\right)$ & 246 & 56 & 36 \\
$\mathrm{Fe}_{\mathrm{o}}\left(\mathrm{g} \mathrm{kg}^{-1}\right)$ & 274 & 160 & 109 \\
Caulinita $\left(\mathrm{g} \mathrm{kg}^{-1}\right)$ & 710 & 710 & 720 \\
Carbono $\left(\mathrm{g} \mathrm{kg}^{-1}\right)$ & 27 & 22 & 21 \\
\hline
\end{tabular}

${ }^{(1)}$ Resultado médio das camadas amostradas; argila determinada pelo método do densímetro; ferro extraído por ditionito-citratobicarbonato e oxalato de amônio e carbono determinado por digestão úmida.

Ciência Rural, v. 33, n. 6, nov-dez, 2003. 


\section{RESULTADOS E DISCUSSÃO}

A quantidade de fósforo extraída pela RTA diminuiu exponencialmente com o aumento no número de extrações sucessivas em todos os solos e camadas amostradas, principalmente na de $0-2,5 \mathrm{~cm}$ (Figura 1). Esse comportamento se deve ao fato de o fósforo ser adsorvido pelos óxidos de ferro e alumínio e arestas quebradas dos filossilicatos com diferentes graus de energia e, portanto, com variação na sua dessortividade. Assim, a primeira extração com RTA retira o fósforo adsorvido com menor energia e à medida que esse se esgota, as quantidades removidas pela resina tornam-se pequenas porque a energia de ligação do fosfato com os colóides aumenta. Em geral, a partir da quarta extração, os valores estabilizaram-

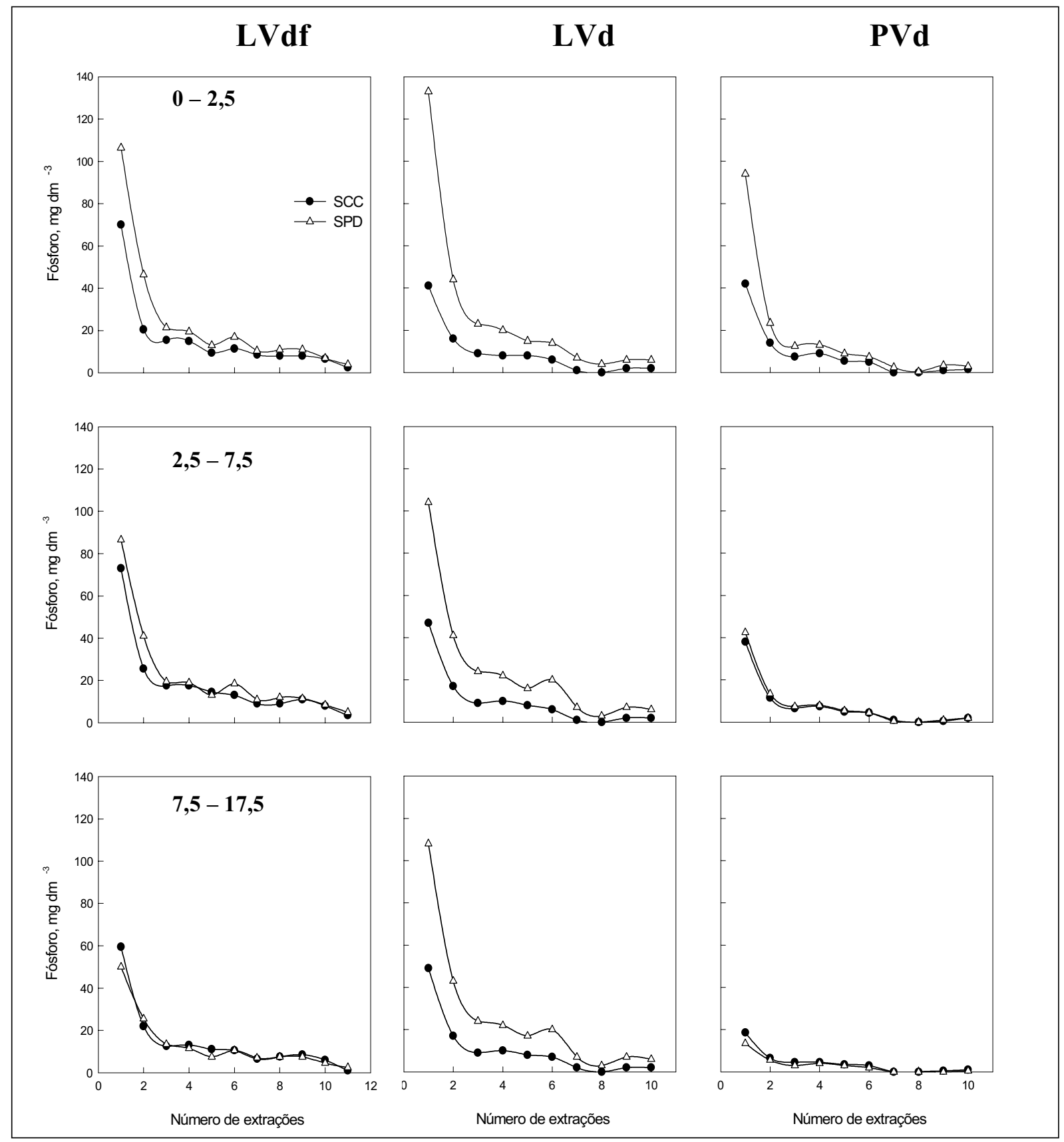

Figura 1 - Dessorção de fósforo por extrações sucessivas com RTA de diferentes profundidades de solos LVdf, LVd e PVd submetidos a sistemas de cultivo.

Ciência Rural, v. 33, n. 6, nov-dez, 2003. 
se, sendo maiores para os solos com maiores teores de argila e óxidos de ferro, devido a sua maior capacidade de tamponamento (Figura 1), como observado por GATIBONI et al. (2002). McKEAN \& WARREN (1996) também verificaram que foram necessárias quatro extrações para que todo o fósforo nativo fosse dessorvido e oito para recuperar o fósforo adicionado via fertilizantes.

No LVdf típico, o solo cultivado sob SPD apresentou maior dessorção máxima de fósforo (b), comparativamente ao SCC, apenas na camada $0-2,5 \mathrm{~cm}$ (Tabela 2). Por outro lado, no SPD o valor de b foi menor na camada $7,5-17,5 \mathrm{~cm}$ em relação às demais camadas, enquanto que no SCC o b foi semelhante em todas as camadas analisadas. Esse comportamento também foi observado na primeira extração com RTA (a) e é atribuído ao acúmulo do fósforo adicionado apenas na camada superficial no solo sob SPD, enquanto no SCC, com o revolvimento, há a redistribuição nas camadas mais profundas (RHEINHEIMER \& ANGHINONI, 2001).

O percentual de fósforo extraído na primeira extração com RTA (a) em relação ao total dessorvível (b) foi semelhante entre os sistemas, sendo 40,38 e $34 \%$ para o SPD e 40,36 e $38 \%$ para o SCC, nas camadas $0-2,5,2,5-7,5$ e $7,5-17,5 \mathrm{~cm}$ do LVdf,

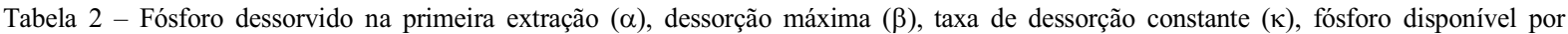
Mehlich 1 e percentual de extração dos métodos RTA e Mehlich 1 em solos de diferentes classes texturais e sistemas de cultivo.

\begin{tabular}{|c|c|c|c|c|c|c|c|}
\hline Camada & Preparo & $\alpha^{(1)}$ & $\beta$ & $\kappa$ & Meh $\mathrm{I}^{(2)}$ & RTA $* 100 / \beta$ & Meh I $* 100 / \beta$ \\
\hline $\mathrm{cm}$ & & \multicolumn{2}{|r|}{$\mathrm{mg} \mathrm{dm} \mathrm{m}^{3}$} & $m g d m^{3} \operatorname{dia}^{-1}$ & $\mathrm{mg} \mathrm{dm}{ }^{3}$ & \multicolumn{2}{|c|}{$\%$} \\
\hline \multicolumn{8}{|c|}{ Latossolo Vermelho distroférrico típico } \\
\hline \multirow[t]{2}{*}{$0-2,5$} & SPD & $98 \mathrm{aA}^{(3)}$ & $248 \mathrm{aA}$ & $0,0407^{\mathrm{ns}}$ & 94 & 40 & 38 \\
\hline & $\mathrm{SCC}$ & $70 \mathrm{bA}$ & $176 \mathrm{bA}$ & 0,0304 & 52 & 40 & 29 \\
\hline \multirow[t]{2}{*}{$2,5-7,5$} & SPD & $76 \mathrm{aA}$ & $223 \mathrm{aA}$ & 0,0324 & 83 & 38 & 37 \\
\hline & SCC & $73 \mathrm{aA}$ & $202 \mathrm{aA}$ & 0,0310 & 61 & 36 & 30 \\
\hline \multirow[t]{2}{*}{$7,5-17,5$} & SPD & $45 \mathrm{aB}$ & $133 \mathrm{aB}$ & 0,0377 & 42 & 34 & 32 \\
\hline & SCC & $60 \mathrm{aA}$ & $157 \mathrm{aA}$ & 0,0320 & 43 & 38 & 27 \\
\hline \multirow[t]{2}{*}{$\mathrm{cv}(\%)$} & & 16,11 & 14,34 & 22,56 & & & \\
\hline & \multicolumn{7}{|c|}{ Latossolo Vermelho distrófico típico } \\
\hline \multirow[t]{2}{*}{$0-2,5$} & SPD & $123 \mathrm{aA}$ & $261 \mathrm{aA}$ & $0,0685^{\mathrm{ns}}$ & 145 & 47 & 56 \\
\hline & SCC & $44 \mathrm{bA}$ & $99 \mathrm{bA}$ & 0,0734 & 37 & 44 & 37 \\
\hline \multirow[t]{2}{*}{$2,5-7,5$} & SPD & $112 \mathrm{aA}$ & $241 \mathrm{aA}$ & 0,0613 & 161 & 47 & 67 \\
\hline & SCC & $47 \mathrm{bA}$ & $105 \mathrm{bA}$ & 0,0677 & 51 & 45 & 49 \\
\hline \multirow[t]{2}{*}{$7,5-17,5$} & SPD & $116 \mathrm{aA}$ & $250 \mathrm{aA}$ & 0,0613 & 69 & 46 & 28 \\
\hline & $\mathrm{SCC}$ & $49 \mathrm{bA}$ & $109 \mathrm{bA}$ & 0,0687 & 40 & 45 & 37 \\
\hline \multirow[t]{2}{*}{ cv $(\%)$} & & 21,43 & 18,42 & 13,20 & & & \\
\hline & \multicolumn{7}{|c|}{ Argissolo Vermelho distrófico típico } \\
\hline \multirow[t]{2}{*}{$0-2,5$} & SPD & $94 \mathrm{aA}$ & $165 \mathrm{aA}$ & $0,0781^{\mathrm{ns}}$ & 146 & 58 & 88 \\
\hline & SCC & $41 \mathrm{bA}$ & $85 \mathrm{bA}$ & 0,0783 & 80 & 49 & 94 \\
\hline \multirow[t]{2}{*}{$2,5-7,5$} & SPD & $42 \mathrm{aB}$ & $84 \mathrm{aB}$ & 0,0823 & 84 & 52 & 100 \\
\hline & SCC & $38 \mathrm{aA}$ & $77 \mathrm{aA}$ & 0,0688 & 69 & 51 & 90 \\
\hline \multirow[t]{2}{*}{$7,5-17,5$} & SPD & $12 \mathrm{aC}$ & $31 \mathrm{aC}$ & 0,0771 & 28 & 38 & 90 \\
\hline & $\mathrm{SCC}$ & $19 \mathrm{aB}$ & $42 \mathrm{aB}$ & 0,0736 & 31 & 45 & 74 \\
\hline $\mathrm{cv}(\%)$ & & 21,43 & 18,42 & 13,20 & & & \\
\hline
\end{tabular}

(1) $\alpha=$ RTA

(2) Meh I = Mehlich 1

${ }^{(3)}$ letras iguais, minúsculas entre sistemas na profundidade e maiúsculas entre profundidades no sistema, não diferem entre si pelo teste de Tukey $(\mathrm{p}<0,05)$.

Ciência Rural, v. 33, n. 6, nov-dez, 2003. 
respectivamente (Tabela 2). Por outro lado, esses resultados indicam que uma única extração com resina não representa o fósforo disponível do solo e que esse é tamponado por outras formas de fósforo, as quais mantêm certo grau de labilidade. Similarmente, CAMPELLO et al. (1994) e GATIBONI et al. (2002) constataram que uma única extração com RTA dessorveu apenas 40 e $37 \%$ do fósforo dessorvível, respectivamente. Os valores da taxa de dessorção constante $(k)$ foram semelhantes entre os métodos de preparo do solo (Tabela 2).

O comportamento das curvas de dessorção de fósforo no LVd típico foi idêntico aos demais solos (Figura 1). Durante as primeiras seis extrações, a quantidade de fósforo foi maior no SPD do que no SCC, em todas as camadas amostradas. Deste modo, tanto a quantidade de fósforo contida na primeira extração quanto à dessorção máxima de fósforo foram muito maiores no SPD do que no SCC (Tabela 2). O percentual de fósforo extraído na primeira extração em relação ao total desorvível foi 47,47 e $46 \%$ para o SPD e 44,45 e $45 \%$ para o SCC, nas camadas $0-2,5$, 2,5-7,5 e 7,5-17,5 cm, respectivamente, sendo, portanto, maiores do que os observadas no LVdf. Isso indica que a capacidade da RTA, na estimativa do fósforo dessorvível, é maior nesse solo comparativamente ao LVdf, estando de acordo com os menores teores de argila (530 e $680 \mathrm{~g} \mathrm{~kg}^{-1}$ ) e óxidos de ferro (56 e $246 \mathrm{~g} \mathrm{~kg}^{-1}$ de $\mathrm{Fe}_{\mathrm{d}}$ para o LVd e LVdf, respectivamente). Similarmente ao observado para o LVdf, as taxas de dessorção constante não diferiram entre os sistemas de cultivo.

No PVd típico, o decréscimo na quantidade de fósforo extraído com o aumento no número de extrações foi mais pronunciado do que nos Latossolos (Figura 1), confirmando o menor poder tampão de fósforo, uma vez que apresenta apenas $220 \mathrm{~g} \mathrm{~kg}^{-1} \mathrm{de}$ argila e $36 \mathrm{~g} \mathrm{~kg}^{-1}$ ferro extraído por ditionito-citratobicarbonato. Os maiores valores de $\mathrm{b}$ foram obtidos na camada superficial, diminuindo drasticamente em camadas mais profundas, especialmente no SPD (Tabela 2). Similarmente aos outros solos, o fósforo dessorvido na primeira extração foi maior no SPD do que no SCC e maior na superfície do que nas demais camadas, o que pode ser atribuído ao não revolvimento do solo sob SPD.

O fósforo extraído na primeira extração com RTA (a) em relação ao total dessorvível (b) foi 58,52 e $38 \%$ para o SPD e 49,51 e $45 \%$ para o SCC, nas camadas $0-2,5,2,5-7,5$ e 7,5-17,5cm do PVd típico, respectivamente (Tabela 2 ).

O decréscimo do valor de a com o aumento da profundidade nos solos sob SPD mostra que o fósforo permanece adsorvido com menor energia nas camadas superficiais do que em camadas mais profundas e, portanto, mais facilmente dessorvido. Este comportamento concorda com OLOYA \& LOGAN (1980), os quais constataram que a quantidade de fósforo removida pela extração seqüencial com resina foi mais rápida, em solos sob SPD, e em maior quantidade na camada $0-2 \mathrm{~cm}$ em relação às camadas de $2-6$ e $6-8 \mathrm{~cm}$.

A análise conjunta dos três solos mostrou que a taxa de dessorção constante aumentou com o decréscimo do teor de argila e ferro dos solos, evidenciando que a dessortividade do fósforo foi maior nos solos mais arenosos. Assim, a primeira extração com RTA representou até $58 \%$ do fósforo dessorvível no solo arenoso enquanto no mais argiloso foi de no máximo $40 \%$ (Tabela 2 ). Um fator que pode ter contribuído para que ainda restasse quantidades significativas de fósforo após a primeira extração com RTA é o fato de o solo ter permanecido inundado entre uma extração e outra, o que pode desencadear processos de oxi-redução, como a dissolução de óxidos de ferro, superestimando o P lábil nas extrações subseqüentes. Porém, não deve ser o mecanismo principal, mas sim que a textura do solo é um fator que interfere na capacidade de extração da RTA e que deve ser considerado na interpretação dos teores de fósforo extraíveis em solos de diferentes classes texturais, similarmente ao procedimento utilizado pela CFS - RS/SC (1994) para interpretar os teores de fósforo extraídos pelo método Mehlich 1 .

O fósforo extraído com o método Mehlich 1 representou 33, 47 e 90\% do máximo dessorvível para os solos LVdf, LVd e PVd, respectivamente, mostrando que a capacidade deste extrator diminui nos solos argilosos devido ao consumo de hidrogênios pelos grupos funcionais não ocupados pelo fósforo nos colóides inorgânicos e readsorção de fósforo aos colóides durante a extração (CAJUSTE \& KUSSOW, 1974). Foi observado que o método Mehlich 1 extraiu menos fósforo em relação ao total dessorvível no solo sob SCC do que o sob SPD e foi devido, provavelmente, ao solo sob SPD conter mais matéria orgânica, a qual diminui a readsorção do fosfato.

\section{CONCLUSÕES}

A primeira extração e a dessorção máxima de fósforo foram maiores na camada superficial do solo sob SPD do que no SCC.

A textura do solo afeta a capacidade de extração da resina trocadora de ânions, pois uma única extração com RTA representou, em média, 38, 46 e 49\% 
do fósforo dessorvível para o solo muito argiloso, argiloso e arenoso, respectivamente.

A estimativa do fósforo disponível pelo extrator Mehlich 1 representou, 32, 46 e $89 \%$ da dessorção máxima de fósforo para o solo muito argiloso, argiloso e arenoso, respectivamente.

\section{AGRADECIMENTOS}

Ao professor João Mielniczuk (UFRGS) e aos pesquisadores Rainoldo Alberto Kochhann (Embrapa-CNPT), Armando Dalla Rosa e João Becker (COTRISA), pela permissão de uso das áreas experimentais, as quais serviram de base para este estudo.

\section{REFERÊNCIAS BIBLIOGRÁFICAS}

BALL-COELHO, B. et al. Short and long-term phosphorus dynamics in a fertilized Ultisol under sugarcane. Soil Sci Soc Am J, Madison, v.57, n.4, p.1024-1034, 1993.

BARROW, N.J. On the reversibility of phosphate sorption by soils. J Soil Sci, Oxford, v.34, p.751-758, 1983.

BECK, M.A.; SANCHEZ, P.A. Soil phosphorus fraction dynamics during 18 years of cultivation on a typic paleudult. Soil Sci Soc Am J, Madison, v.58, p.1424-1431, 1994.

CAJUSTE, L.J.; KUSSOW, W.R. Use and limitations of the North Carolina method to predict available phosphorus in some oxisols. Trop Agric, Trinidad, v.51, p.246-252, 1974.

CAMPELLO, M.R. et al. Avaliação da reversibilidade de fósforo não lábil para lábil em solos com diferentes características. $\mathbf{R}$ Bras Ci Solo, Campinas, v.18, p.157-165, 1994

CFS - RS/SC COMISSÃO DE FERTILIDADE DO SOLO - RS/ SC. Recomendação de adubação e calagem para os estados do Rio Grande do Sul e Santa Catarina. 3. ed. Passo Fundo : SBCS, 1994. 224p.

CONTE, E. Atividade de fosfatase ácida e formas de acumulação de fósforo pela aplicação de fosfato em solo no sistema plantio direto. 2001. 65f. Dissertação (Mestrado em Ciência do Solo) - Programa de Pósgraduação em Ciência do Solo, Universidade Federal do Rio Grande do Sul.

DAROUB, S.H.; PIERCE, F.J.; ELLIS, B.G. Phosphorus fractions and fate of Phosphorus-33 in soils under plowing and no-tillage. Soil Sci Soc Am J, Madison, v.64, p.170-176, 2000

EMBRAPA - Centro Nacional de Pesquisa de Solos. Sistema Brasileiro de Classificação de Solos. Brasília : EMBRAPA, 1999. 412p.

GATIBONI, L.C. et al. Quantificação do fósforo disponível por extrações sucessivas com diferentes extratores em Latossolo Vermelho distroférrico. R Bras Ci Solo, Viçosa, 2002 (no prelo).

GUERTAL, E.A. et al. Differential phosphorus retention in soil profiles under no-till crop production. Soil Sci Soc Am J, Madison, v.55, p.410-413, 1991.
GUO, F.; YOST, R.S. Partitioning soil phosphorus into three discrete pools of differing availability. Soil Sci, Oxford, v.163, p.822-833, 1998

GUO, F. et al. Changes in phosphorus fractions in soils under intensive plant growth. Soil Sci Soc Am J, Madison, v. 64, p.16811689, 2000.

HAGGAR, J.P. et al. Phosphorus availability under alley cropping and mulched and unmulched sole cropping systems in Costa Rica. Plant Soil, Dordrecht, v.137, p.275-283, 1991

HEDLEY, M.J.; STEWART, J.W.B.; CHAUHAN, B.S. Changes in inorganic and organic soil phosphorus fractions induced by cultivation practices and by laboratory incubations. Soil Sci Soc Am J, Madison, v.46, p.970-976, 1982.

HUE, N.V. Effects of organic acids/anions on P sorption and phytoavailability in soils with different mineralogies. Soil Sci, Oxford, v.152, p.463-471, 1991.

McKEAN, J.; WARREN, G.P. Determination of phosphate desorption characteristics in soils using sucessive resin extractions. Commun Soil Sci Plant Anal, New York, v.27, p.2397-2417, 1996.

MURPHY, J.; RILEY, J.P. A modified single solution method for the determination of phosphate in natural waters. Anal Chim Acta, Oxford, v.27, p.31-36, 1962.

OLOYA, T.O.; LOGAN, T.J. Phosphate desorption from soils and sediments with variyng levels of extractable phosphate. J Environ Qual, Madison, v.9, p.526-531, 1980.

PARFITT, R.L. Phosphate reactions with natural allophane, ferrihydrite and goethite. J Soil Sci, Oxford, v.40, p.359-369, 1989.

PARFITT, R.L.; ATKINSON, R.J.; SMART, R.C. The mechanism of phosphate fixation by iron oxides. Soil Sci Soc Am J, Madison, v.39, p.837-841, 1975.

RHEINHEIMER, D.S.; ANGHINONI, I. Distribuição do fósforo inorgânico em sistemas de manejo de solo. Pesq Agropec Bras, Brasília, v.36, p.151-160, 2001.

RHEINHEIMER, D.S.; ANGHINONI, I.; KAMINSKI, J. Depleção do fósforo inorgânico de diferentes frações provocada pela extração sucessiva com resina em diferentes solos e manejos. R Bras Ci Solo, Viçosa, v.24, p.345-354, 2000.

RYDEN, C.J.; McLAUGHLIN, J.R.; SYERS, J.K. Mechanism of phosphates sorption by soils and hydrous ferric oxide gel. J Soil Sci, Oxford, v.28, p.72-92, 1977.

SIBRANDA, H.M.; YOUNG, S.D. Competitive adsorption of humus acids and phosphate on goethite, gibsite and two tropical soils. J Soil Sci, Oxford, v.37, p.197-204, 1986.

TEDESCO, M.J. et al. Análises de solo, planta e outros materiais. 2. ed. Porto Alegre : Departamento de Solos - UFRGS, 1995. 174p. (Boletim técnico de Solos, 5).

TIESSEN, H.; SALCEDO, I.H.; SAMPAIO, E.V.S.B. Nutrient and soil organic matter dynamics under shifting cultivation in semi-arid northeastern Brazil. Agric Ecos and Env, Amsterdan, v. 39, p.139-151, 1992. 